\title{
A Pilot Trial to Predict Frailty Syndrome: The Japanese Health Research Volunteer Study
}

Authors:

Nobutaka Doba, ${ }^{1}$ Yasuharu Tokuda, ${ }^{2}$ Nathan E Goldstein, ${ }^{3}$ Toshio Kushiro, ${ }^{4}$ and Shigeaki Hinohara, ${ }^{5}$

Affiliations:

${ }^{1}$ Division of Research and Education, Life Planning Center Foundation, Sasakawa Kinen Kaikan, Eleventh Floor, 12-12, Mita 3-chome, Minato-ku, Tokyo, 108-0073

Japan, E-mail: doba@krd.biglobe.ne.jp

2 Department of Medicine, Mito Kyodo General Hospital, University of Tsukuba

3-2-7 Miya-machi, Mito City, Ibaraki, 310-0015 Japan, E-mail:

yasuharu.tokuda@gmail.com

${ }^{3}$ Brookdale Department of Geriatrics and Palliative Medicine, Mount Sinai School of Medicine and the James J Peters VA Medical Center Bronx, NY, USA, E-mail:

Nathan.goldstein@mssm.edu

${ }^{4}$ Center for Health Evaluation and Promotion, Nihon University School of Medicine, 1-7-3, Kanda Surugadai, Chiyoda-ku, Tokyo, Japan 101-0062, Japan,

Kushiro@med.nihon-u.ac.jp

${ }^{5}$ Life Planning Center Foundation, Sasakawa Kinen Kaikan, Eleventh Floor, 12-12, Mita 3-chome, Minato-ku, Tokyo, 108-0073 Japan, E-mail:

shosler@mrj.biglobe.ne.jp

Corresponding Author:

Nobutaka Doba, MD, PhD

Division of Research and Education

Life Planning Center Foundation

Sasakawa Kinen Kaikan, Eleventh Floor

12-12, Mita 3-chome, Minato-ku, Tokyo, 108-0073 Japan

Fax: 3-3455-1035, Phone: 3-3454-5068, E-mail: doba@krd.biglobe.ne.jp

Running headline: Prediction of frailty in older Japanese adults 


\section{Abstract}

Most definitions of frailty utilize US populations in their development. The concept of frailty has not been well studied in Japan, which has the largest percentage of older patients (per capita) in the world. We created a 5-year prospective cohort study of community-dwelling older Japanese adults. Participants were not frail at baseline, based on our definition adapted from the Canadian Study for Health and Aging Clinical Frailty Scale. Participants underwent a comprehensive geriatric assessment (CGA) at baseline, and final assessments were either in person or via mailed survey. We enrolled 407 individuals (184 men, mean age $78 \pm 4$ years; 223 women, mean age $77 \pm 4$ years). Sixty-five participants met criteria for frailty by the end of the study. In univariate analyses, eighteen separate parameters were associated with frailty, some of which included: age, gender, handgrip, timed walk, systolic blood pressure, pulse pressure, cognitive status, living alone, and hearing deficits. In multivariate analyses, the following elements remained associated with frailty: timed walk, pulse pressure, cognition deficits and hearing deficits. We established cut-off points for timed walk (5 meters/3 seconds) and pulse pressure (60 $\mathrm{mmHg}$ ). We then created a simple additive score for these four factors (present $=1 ;$ absent $=0$ ). A score of 0 had a $93 \%$ negative predictive value for frailty while a score of 4 had a $70 \%$ positive predictive value. While further study is needed, this work creates an easy-to-administer tool that may be generalizable to other populations. 
Keywords: frailty, prediction, gait speed, pulse pressure, cognitive deficits, hearing deficits 


\section{Introduction}

Health maintenance and health promotion among older adults have become major societal issues worldwide, especially among Western nations (Cassel, 2009; Cruz-Jentroft et al, 2009). Furthermore, it is believed that such issues might have important cost and outcome benefits for society (Ackermann et al, 2008; Goetzel et al, 2007; Meng et al, 2009; Wieland, 2003). Although a comprehensive geriatric assessment (CGA) has long been used as the standard of care in the field of geriatrics (Li, 2010), another less formal and simpler types of assessment may be useful for active, relatively healthy older individuals (Jones et al, 2004,2005; Searle et al, 2008). In particular, proactively assessing these older adults for frailty may help determine which subjects need interventions to prevent poor health outcomes. However, a widely accepted, clinically applicable and easy-to-use definition of frailty has not yet been established. Fried and others (Fried et al, 2001) proposed the concept that frailty is a clinical phenotype characterized by several variables, although some of these variables (such as grip strength, timed walk) may not be readily clinically available. The Canadian Study for Health and Aging Clinical Frailty Scale (CSHA-CSF), on the other hand, uses symptoms and signs that do not require sophisticated clinical measurements (Rockwood et al, 2005). Controversy continues as to which of these models may be the most useful, and further research is needed to determine how the definition of frailty used relates to factors such as socio-economic status, comorbidities, and cognitive and sensory impairments (Lang et al, 2009). 
In 2000, the "New Elderly Citizen Movement" was initiated at the Life Planning Center Foundation in Tokyo, Japan, with the goal of encouraging older adults to make lifestyle changes so they could remain active and productive. Within this group, a research cohort was established and as of 2002, the cohort has about 3,000 members. At baseline, these individuals were relatively healthy and active, although some had co-morbid illnesses that did not affect their functional status or ability to live independently. The details of their medical conditions and health-related behaviors have been reported elsewhere (Doba et al, 2011; Hinohara et al, 2005). The "Health Research Volunteer Study" was a cohort study within this program that examined the clinical phenotype and other factors associated with the development of frailty. This manuscript describes the factors associated with frailty in this study and proposes the validation of a prediction rule for frailty in this unique cohort of Japanese individuals. 


\section{Methods}

\subsection{Definition and assessment of frailty}

A consensus on the concept and diagnostic criteria for frailty has not yet been established. While Fried and others (Fried et al, 2001) have done the most work on defining the frailty phenotype, their definition was not suitable for our population. In addition to being frail, this is in part due to the fact that some older adults in our study were not available for in-person assessments (e.q. to determine walking speed or arip strength) at the end of the study because they had moved away or did not have the assistance they needed to be able to come to our clinic.

Because of these limitations, we chose to use the CSHA-CFS definition of frailty, which clusters individuals along a continuum of being completely dependent and frail to completely healthy (Rockwood et al, 2005). The CSHA-CFS is defined as follows: very fit, robust, active, energetic, and highly motivated; well, without active disease, but less fit; well, with treated comorbid disease; apparently vulnerable, not dependent, but beginning to slow down; mildly frail, dependent on others for Instrumental Activity of Daily Living (IADLs); moderately frail, help is needed with IADLs; and severely frail, completely dependent or terminally ill. Both the probability of survival and the ability to remain independent measured by being able to avoid placement in a long-term care were significantly different among the seven groups during a 70-month follow-up period. These differences were especially obvious between the group with a score of 3 and the group with a score 4 . Although various 
frailty models are available, and assessment of frailty remains very heterogeneous (Abellan van Kahn et al, 2008; Lang et al, 2009), the CSHA Clinical Frailty Scale is inline with the National Care Policy for Japan and could be adopted as one of the more widely used scales in both clinical and community practice (Chan et al, 2009). We used the CSHA-CFS to dichotomize subjects into two groups at the end of the 5-year follow-up period: a non-frail group comprised of those with scores from 1 to 3 and a frail group comprised of those with a score of 4 to 7 .

\subsection{Subjects}

Criteria for being included in this analysis were: having contributed data for the 5-year period ending in 2011, having a score of 1 to 3 on the CHSA-CFS at the baseline assessment, and having had a stable weight for the 6 months before study entry. From the entire cohort of 3,000 members at the Life Planning Center 407 subjects were enrolled in the study based on the following entry criteria: age $>70$ years, well-controlled comorbid illness, sufficiently independent in IADLs, and having active social connections (Entry criteria adapted from Rowe et al, 1998). All subjects were community-dwelling and were independent in their Activities of Daily Living (ADLs) and IADLs at baseline. We excluded patients if they had active chronic infective, inflammatory, neoplastic or other moderate to severe chronic diseases. Patients with stable medical conditions or who were receiving conventional medications for those conditions (e.g. antihypertensives, lipid-lowering agents, or oral hypoglycemic medications) were not excluded. Study endpoints 
were death, development of frailty, drop-out, or study termination.

At the end of the 5-year study period, all enrolled subjects were contacted and asked to come to the Life Planning Center for a final assessment. When subjects were unable because they were too ill or otherwise unavailable, we contacted them or their caregivers via telephone or mail. Subjects who could not be contacted at the final assessment were considered dropouts and were removed from the study. Written informed consent was obtained from all the participants, and ethical permission was obtained from the Committee of the Japan Society of Health Evaluation and Promotion.

\section{2-3. Determination of Frailty}

The study committee consisting of 21 members and included physicians, sociologists, psychologists, statisticians, dieticians, nurses and medical technicians who held regular meetings three times a year. Two physicians made the determination of frailty based on the pre-defined criteria, and these decisions were reported to the larger committee meeting where the final determination was accepted by a consensus process. When there was a lack of clarity as to whether a subject had a score of three or four ( 4 cases, $6 \%$ of subjects), the following additional criteria were used to make the frailty determination: exercise tolerance (inability to walk $800 \mathrm{~m}$ without resting and/or to climb 10 steps with ease), fatigue, weight loss more than $5 \mathrm{~kg}$ for past 1 year, fall with or without fracture and 
decreased physical strength. When one of these rare cases had two or more of these elements, they were classified as a score of 4 . In addition, in years two and four, clinical updates were obtained via written surveys, telephone interviews or through other clinical avenues.

\section{2-4. Assessment and Measurements}

Interview materials were sent to all participants in advance, and they completed the instruments on their own. They then brought these forms in to be reviewed and confirmed by one of 4 trained study nurses in one-on-one conversations with subjects. Questions were multiple choice in nature, and response options were: none (0), slightly (1), obviously (2) [translated from Japanese]. For example, when asked about difficulties with hearing, 0 signifies no problems, 1 signifies slight problems in mildly noisy situation, and 3 signifies obvious hearing difficulty in any situation. All study procedures were carefully documented and monitored.

The survey instrument consisted of four parts: 1) a section assessing daily activities and changes in physical and cognition function; 2) a section reviewing their current medical conditions and treatments; 3) depression screening and 4) a detailed dietary assessment. Cognitive assessment was confirmed using the Minimum Data Set cognitive performance scale by Morris and others (Morris et al,1994). After completing these assessments, all subjects underwent a physical examination performed by the attending physicians at the Life Planning Center Clinic in Tokyo, who are specialized in internal medicine and cardiology. 
As part of these assessments, the following parameters were obtained: height $(\mathrm{cm})$, weight $(\mathrm{kg})$, body mass index, body fat ratio (\%; bio-impedance method using TBF-110/210 equipment from TANITA), total body fat mass $(\mathrm{kg})$, total body nonfat mass (kg; body weight - total body fat mass), and maximum mid-arm and mid-calf circumferences $(\mathrm{cm})$. Skin-fold measurements $(\mathrm{mm})$ were performed on the dorsal aspect of the triceps and the muscular area of the mid-portion of the upper arm. Other functional measurements that were obtained included: a single measurement of grip strength of the dominant hand ( $\mathrm{kg}$ with Grip D, T.K.K.5401), timed walk (number of seconds to walk 5 meters using a start/stop methodology), resting metabolic ratio $(\mathrm{kcal} / \mathrm{min})$, bone mineral density of the $2 \mathrm{nd}$ to $4^{\text {th }}$ lumbar vertebrae (DEXA: $\mathrm{g} / \mathrm{cm}^{2}$ ). Cardiovascular parameters assessed included: the systolic, diastolic, and pulse pressures ( $\mathrm{mmHg}$ ): heart rate (beats/minute); and brachial-ankle pulse wave velocity ( $\mathrm{cm} / \mathrm{second})$. Laboratory tests included: complete blood count, creatinine, blood urea nitrogen, serum electrolytes $(\mathrm{Na}, \mathrm{K})$, total cholesterol, total protein, albumin, hemoglobin A1c, serum osmolality, cortisol, luteinizing hormone, free testosterone for men, dehydroepiandrosterone sulphate, C-reactive protein, and interleukin-6. Socio-demographic data collected included: whether the subject lived with a spouse (yes/no); whether the subject lived with other persons (yes/no); frequency of going out (frequency/week: frequent $\geqq 3$ days, rare $\leqq 2$ days); anorexia (yes/no); insomnia (yes/no); exercise tolerance (ability to walk $800 \mathrm{~m}$ without resting and ability to climb 10 steps with ease); subjective 
cognitive changes during the past 3 years (none, slight, or obvious); mood changes (none, slightly depressed, or depressed); fatigability (none, slight, or obvious); history of falls or fracture during the past 3 years (yes/no); hearing deficits (none, slight, or obvious); poor distance vision (none, slight, obvious) and decreased physical strength (none, slight, or obvious). This comprehensive geriatric assessment was performed at both the baseline and the study termination visits. A simplified version of the functional status questionnaire was sent to all the participants at the end of the second and fourth years to confirm their vital status (dead/alive), level of function, and degree of frailty.

\subsection{Statistical analyses}

All the data were analyzed using SPSS version 15.0J (Tokyo, Japan). Parametric variables were expressed as the mean \pm 1 SD and were analyzed using the Student t-test. Non-parametric variables were analyzed using the Fisher exact test. The correction for the type 1 error was applied by Bonferroni's methods. A stepwise multiple logistic regression analysis was used to identify factors independently associated with the outcome of frailty. For significant parametric factors identified using the multiple logistic regression analysis, ROC curves were constructed to determine a cut-off point with an acceptable sensitivity and specificity. Furthermore, using the factors identified as significant in the multiple logistic regression analysis, a predictive model for frailty syndrome was developed and its negative and positive predictive values were determined. A two-tailed $P$ value less than 0.05 was 
considered significant. 


\section{Results}

\subsection{Description of the Study Population}

The mean age of the 407 subjects at baseline was $78 \pm 4$ years, with no difference between men and women (184 men, mean age of $78 \pm 4$ years; 223 women, mean age of $77 \pm 4$ years; $p=0.349$ ). During the 5 -year follow-up period, 22 patients died (Table 1); there were no significant differences in terms of gender or age of deceased patients. The major cause of death was cancer $(n=8,36 \%)$ followed by cardiovascular and/or cerebro-vascular accidents ( $n=5,23 \%)$. Overall, the dropout rate was $8.4 \%$ (Table 1); there were no significant differences in age or gender between those who stayed in the study and those who dropped out. There were no other statistically significant differences between those who dropped out in terms of the measured non-parametric and parametric variables.

\subsection{Incidence of frailty}

As per the inclusion criteria, none of the subjects who entered the HRVS were frail at baseline. After the 5-year follow-up period, 65 subjects were frail according to the CSHA-CFS (Table 1). Of these, 35 subjects had a frailty score of 4, 25 had a score of 5,2 subjects were classified as level 6 , and 3 subjects had a score of 7 .

\subsection{Prediction of frailty}

Univariate analyses of the differences between non-frail and frail subjects revealed a slight but statistically significant difference in subjects' age (78 \pm 4 years for men 
and $77 \pm 4$ years for women at baseline; $p=0.049$; see Table 2) and gender, with 19 men and 46 women meeting the criteria for frailty $(p=0.006$; see Table 3$)$. Univariate analyses also revealed significant differences between the non-frail and frail groups for the following parametric variables: height, weight, upper arm muscle area, calf circumference, bone mineral density (BMD), hand-grip of dominant side, slow timed walk, systolic pressure, pulse pressure, hemoglobin, luteinizing hormone and dehydroepiandrosterone sulphate (see Table 2). Significant differences for the following non-parametric variables were also observed: gender, cognitive changes, hearing deficits, history of a fall, living with a spouse, and urinary incontinence (see Table 3).

In the multivariate analysis, the following five variables were significantly associated with frailty: pulse pressure, cognitive changes, slow timed walk, calf circumference, and hearing deficits. The ROC curves for the three parametric variables revealed the following cut-off points: 3.0 seconds/ 5 meters for timed walk, $60 \mathrm{mmHg}$ for pulse pressure, and $35 \mathrm{~cm}$ for calf circumference. A logistic model was assembled using these five variables, and the following four variables were found to be statistically significant for the prediction of frailty: pulse pressure $(>=60 \mathrm{mmHg})$, subjective cognitive changes (present), slow timed walk ( $>3$ seconds $/ 5$ meters) and presence of hearing deficits (see Table 4).

Since the magnitudes of the odds ratios for the four explanatory variables were similar (see Table 4), a predictive scoring model was developed that consisted of simply adding the presence of elements together (present, 1; absent, 0) (see Table 
5). In this scoring system, a pulse pressure >= $60 \mathrm{mmHg}$ was given 1 point; presence of cognitive changes was given 1 point; slow timed walk was given 1 point if it took more than 3 seconds to walk 5 meters; and hearing deficits were scored 1 point if present. This model for frailty showed a $93 \%$ negative predictive value for a score of $0(n=55$, non-frailty $=51)$ and a $70 \%$ positive predictive value for a score of $4(\mathrm{n}=10$, frailty=7). The ROC area of this model was $0.734(95 \% \mathrm{Cl}, 0.661-0.806)$. 


\section{Discussion}

This is the first longitudinal cohort study of community-dwelling older adults examining the incidence of frailty in Japan. We found the incidence of frailty in this population to be approximately $16.0 \%$ during the 5 year follow-up period; slow timed walk, pulse pressure, cognitive status, and hearing deficits were significant predictors of the frailty syndrome. We also created and validated a simple prediction scale for frailty.

\subsection{Biological significance of variables associated with frailty}

In our study, the incidence of frailty was 2.3 times higher among women than among men, and this is in line with what previous studies have reported. This gender difference has traditionally been explained as being related to sarcopenia as well as neuroendocrine and/or immune deficiencies (Abdel-Rahman et al, 2009; Byalow et al, 2007; Maggio et al, 2010; Sharifi et al, 2005, Walstone et al, 1999). For example, muscle mass has been assumed to be larger among men than among women; therefore, a longer time is required for the development of sarcopenia in men than in women. Another element is that growth hormones and androgens also affect muscle mass, thus making it more likely that women would lose muscle mass. Finally cortisol dysregulation, which is seen more frequently in women than in men, may also play a role in the development of frailty by gender.

Decreased movement at baseline is another characteristic finding in frail elderly 
individuals, and this characteristic can be evaluated using the timed walk or other assessments of gait speed (Working Group on Functional Outcome Measure for Clinical Trials, 2008, Abellum van Kan et al, 2009). Our finding that having a slow timed walk was one of the most significant predictors of frailty. This is consistent with that reported in the literature, and may be related to both morphological and functional declines in the musculo-skeletal system (Drey et al, 2011; Theou et al, 2008) as well as cognitive deficits (Abellan van Kan,2011; ljmker, 2011).

The relation between frailty and cardiovascular disease is well established, although most studies focus on ischemic heart disease and heart failure (Afilalo et al, 2009; Cacciatoreetal,20005). Only a few studies have examined the relationship between hypertension and frailty (DiBriet al, 2004; Gray et al, 2009). In our study, the multivariate analysis using both forward and backward stepwise regression revealed the pulse pressure to be a significant predictor of frailty. For the past several years, discussions have focused on the utility of antihypertensive treatment for patients over the age of 80 years, and several studies have supported this treatment (Forette et al, 2002; Mancia et al, 2008; O'Rourk, 2005; Yano et al, 2011). However, adequate blood pressure levels for the treatment of very elderly hypertensive populations have not been described. The Japanese Society of Hypertension Committee has recommended $140 / 90 \mathrm{mmHg}$ as being the upper acceptable limits for hypertension in older adults, but this recommendation has not been backed with evidence from studies of adults in Japan (Ogihara etal, 2009). 
Thus our study may add further evidence for close monitoring of blood pressure in older Japanese adults. although further study about the relationship of controlling hypertension and the development of frailty is needed.

Our model includes sensory impairment as a potential predictor of frailty. This is an important distinction, as other models focus almost exclusively on physiologic parameters but not common geriatric syndromes. Thus our model provides potential insight into the role of geriatric syndromes in the development of frailty, which is currently relevant given the increasing worldwide health initiatives that have begun to focus on older adults who require assistance with their ADLs (Lang, 2009) The findings from our pilot study concur with those previously published by Rockwood and colleagues (Searle, 2008). In addition, our relationship of sensory impairment to frailty is consistent with that of others in the literature (Cigolle, 2007; Gurina, 2011;Lang, 2009). However, in our study, pure tone audiometry with both $2,000 \mathrm{~Hz}$ and $4,000 \mathrm{~Hz}$ did not reveal significant differences between frail and non-frail subjects. We hypothesize that peripheral auditory receptive mechanisms are intact and the difficulty in hearing may be related to other central nervous system factors or cognitive function in these older adults (Gates, 2008; Idrizbegovic, $2011)$.

\subsection{Study limitations}

This study was a single-center prospective observational cohort study, and the 
inclusion criteria clearly defined the participants as being healthy and independent at baseline. In addition, all the participants in the study were members of the New Elderly Citizens Movement, the primary purpose of which is to encourage older adults to lead not only physically, but also socially, and spiritually active lives. As a result, there may have been a selection bias to include participants who were interested in not becoming frail. While we had specific reasons for choosing the CSHA-CFS based on both Japanese culture as well as our population in particular, some have questioned its use. Another limitation is that we could not obtain some data on a portion of the frail population at the end of the study because they were unable to visit the Life Planning Center Clinic for a final assessment. Additionally, of the subjects who were not able to visit the center at the end of the study, 45 were judged as frail, and this represents a relatively large portion of the total population of frail subject. While this is a limitation, its impact is lessened somewhat by the fact that it was easy to discern the frailty status of these individuals; that is, there was no difficulty in scoring these 45 subjects who are not interviewed in person. Also, since our model would be that our sample size of frailty was small (65 subjects), it is clear that further study is needed to validate our frailty index in other large scale populations of older adults. Even though our population was from a single center, the evaluation of the frailty phenotype in this group of Japanese older adults helps to explore differences in the ways the CHSA scale diagnoses frailty in non-Caucasian populations. Our future work will need to further elucidate the inter-relationship of these factors as well through another 5 year follow-up study to 
the same cohort, and also some trials for preventative approach to subjects defined at risk could be designed.

\subsection{Conclusion}

The concept of frailty undoubtedly plays an important role in terms of health promotion and maintenance, but also in terms of improving caregiver burden and decreasing costs. This importance will only become increasingly apparent in the future given the nature of rapidly aging societies across the world. Although numerous studies have examined models of frailty and reported on its natural outcomes, studies on its incidence have been reported less often. This is especially true for populations outside the United States. While further work is needed to validate our finding, these results describe a specific phenotype that may be easily applied to predict frailty and thus improve health outcomes for older adults. 


\section{ACKNOWLEDGEMENTS}

The research reported in this paper was supported by the institutional research fund from the Life Planning Center, a not-for-profit organization. The authors have no conflict of interest to disclose. We thank all the participants who joined the study as well as the members of the study committee. 


\section{REFERENCES}

1. Abdel-Rahman E, Holly JL. A review of the effects of growth hormone changes on symptoms of frailty in the elderly with chronic kidney disease. Semin Dial. 2009; 22:532-538. [Pub Med]

2. Abellan van Kan G, Rolland $Y$, Andrieu S, Bauer J, Beauchet O, Bonnefoy M, Cesari M, Donini LM, Gillette Guyonnet S, Inzitari M, Nourhashemi F, Onder G, Ritz P, Salva A, Visser M, Vellas B. Gait speed at usual speed as a predictor of adverse outcomes in community-dwelling older people an International Academy on Nutrition and Aging (IANA) task force. J Nutr Health Aging. 2009; 13: 881-889. [Pub Med]

3. Abellan van Kan G, Rolland Y, Bergman H, Morley JE, Kritchevsky SB, Vellas B: The I.A.N.A. task force on frailty assessment of older people in clinical pratice. J Nutr Health Aging 2008; 12: 29-37. [Pub Med]

4. Abellan van Kan G, Rolland Y, Gillette-Guyonnet S, Gardette V, Annweiler C, Beauchet O, Andrieu S, Vellas B. Gait Speed, Body Composition, and Dementia. The EPIDOS-Toulouse Cohort. J Gerontol A Biol Sci Med Sci. 2012; 67A:425-432. [Pub Med]

5. Ackermann RT, Williams B, Nguyen HQ, Berke EM, Maciejewski ML, LoGerfo JP. Healthcare cost differences with participation in a community-based group physical activity benefit for medicare managed care health plan members. J Am Geriatr Soc. 2008;56:1459-1465. [Pub Med]

6. Afilalo J, Karunananthan S, Eisenberg MJ, Alexander KP, Bergman H. Role of frailty in patients with cardiovascular disease. Am J Cardiol. 2009;103:16161621. [Pub Med]

7. Bylow K, Mohile SG, Stadler WM, Dale W. Does androgen-deprivation therapy accelerate the development of frailty in older men with prostate cancer ?: a conceptual review. Cancer. 2007;110:2604-2613. [Pub Med]

8. Cacciatore F, Abete P, Mazzella F, Viati L, Della Morte D, D'Ambrosio D, Gargiulo G, Testa G, Santis D, Galizia G, Ferrara N, Rengo F. Frailty predicts long-term mortality in elderly subjects with chronic heart failure. Eur J Clin Invest. 2005;35: 723- 730. [Pub Med]

9. Cassel CK. Policy for an aging society: a review of systems. JAMA. 2009; 302: 
2701-2702. [Pub Med]

10. Chan DC, Tsou HH, Chen CY. Validation of the Chinese-Canadian study of health and aging clinical frailty scale (CSHA-CFS) telephone version. Arch Gerontol Geriatr. 2009;50:e74-80. [Pub Med]

11. Cigolle CT, Langa KM, Kabeto MU, Tian Z, Blaum CS. Geriatric conditions and disability: the Health and Retirement Study. Ann Intern Med. 2007; 7;147:156-164. [Pub Med]

12. Cruz-Jentoft AJ, Franco A, Sommer P, Baeyens JP, Jankowska E, Maggi A, Ponikowski P, Rys A, Szczerbinska K, Michel JP, Milewicz A. Silver paper: The future of health promotion and preventive actions, basic research, and clinical aspects of age- related disease : a report of the European Summit on Age-Related Disease. Aging Clin Exp Res. 2009;21:376-385. [Pub Med]

13. Di Bari M, van de Poll-Franse LV, Onder G, Kritchevsky SB, Newman A, HarrisTB, Williamson JD, Marchionni N, Pahor M. Antihypertensive medications and differences in muscle mass in older persons: the Health, Aging and Body Composition Study. J Am Geriatr Soc. 2004;52:961-966. [Pub Med]

14. Doba N, Hinohara S, Yanai H, Saiki K, Takagi H, Tsuruwaka M, Hirano M, Matsubara $\mathrm{H}$. The New Elder Citizen Movement in Japan. In: Matsumoto Y, ed. Faces of Aging: The lived experiences of the elderly in Japan. Stanford, Calif: Stanford University Press; 2011:36-59.

15. Drey M, Pfeifer $\mathrm{K}$, Sieber CC, Bauer JM. The Fried frailty criteria as inclusioncriteria for a randomized controlled trial: personal experience and literature review. Gerontology. 2011;57:11-18. [Pub Med]

16. Forette F, Seux ML, Staessen JA, Thijs L, Babarskiene MR, Babeanu S, Bossini A, Fagard R, Gil-Extremera B, Laks T, Kobalava Z, Sarti C, Tuomilehto J, Vanhanen H, Webster J, Yodfat Y, Birkenhger WH; Systolic Hypertension in Europe Investigators. The prevention of dementia with antihypertensive treatment: new evidence from the Systolic Hypertension in Europe (Syst-Eur) study. Arch Intern Med. 2002 Oct 14;162(18):2046-2052. [Pub Med]

17. Fried LP, Tangen CM, Walston J, Newman AB, Hirsch C, Gottdiener J, Seeman T, Tracy R, Kop WJ, Burke G, McBurnie MA; Cardiovascular Health Study Collaborative Research Group. Frailty in older adults: evidence for a phenotype. J Gerontol A Biol Sci Med Sci. 2001;56:M146-156. [Pub Med] 
18. Gates GA, Anderson ML, Feeney MP, McCurry SM, Larson EB. Central auditory dysfunction in older persons with memory impairment or Alzheimer dementia. Arch Otolaryngol Head Neck Surg. 2008;134:771-777.

19. Goetzel RZ, Shechter D, Ozminkowski RJ, Stapleton DC, Lapin PJ, McGinnis $\mathrm{JM}$, Gordon CR, Breslow L. Can health promotion programs save Medicare money? Clin Interv Aging. 2007;2:117-122. [Pub Med]

20. Gray SL, LaCroix AZ, Aragaki AK, McDermott M, Cochrane BB, Kooperberg CL, Murray AM, Rodriguez B, Black H, Woods NF; Women's Health Initiative Observational Study. Angiotensin-Converting Enzyme Inhibitor Use and Incident Frailty in Women Ages 65 and Older: Prospective Findings from the Women's Health Initiative Observational Study. J Am Geriatr Soc. 2009; 57: 297-303. [Pub Med]

21. Gurina NA, Frolova EV, Degryse JM. A roadmap of aging in Russia: the prevalence of frailty in community-dwelling older adults in the St. Petersburg district--the "Crystal" study. J Am Geriatr Soc. 2011;59:980-988. [Pub Med]

22. Hinohara $\mathrm{S}$, Doba $\mathrm{N}$. The future profile of health promotion and disease prevention in Japan. Methods Inf Med. 2005;44: 342-347. [Pub Med]

23. Idrizbegovic E, Hederstierna C, Dahlquist M, Kompfe Nordstrom C, Jelic $V$, Rosenhall $U$. Central auditory function in early Alzheimer's disease and in mild cognitive impairment. Age Ageing. 2011;40:249-254. [Pub Med]

24. Ijmker T, Lamoth CJ. Gait and cognition: The relationship between gait stability and variability with executive function in persons with and without dementia. Gait Posture. 2012;35:126-30. [Pub Med]

25. Jones D, Song X, Mitnitski A, Rockwood K. Evaluation of a frailty index based on a comprehensive geriatric assessment in a population based study of elderly Canadians. Aging Clin Exp Res. 2005;17:465-471. [Pub Med]

26. Jones $D M$, Song $X$ Rockwood $K$. Operationalizing a frailty index from a standardized comprehensive geriatric assessment. J Am Geriatr Soc. 2004; 52:1929-1933. [Pub Med]

27. Lang PO, Michel JP, Zekry D: Frailty syndrome: A transitional state in a dynamic process. Gelontology 2009; 55: 539-549. [Pub Med] 
28. Li CM, Chen CY, Li CY, Wang WD, Wu SC. The effectiveness of a comprehensive geriatric assessment intervention program for frailty in community-dwelling older people: a randomized, controlled trial. Arch Gerontol Geriatr. 2010;50 Suppl 1:S39-42. [Pub Med]

29. Mancia G, Grassi G. Management of very elderly hypertensives: the HTYVET study. Aging Clin Exp Res. 2008; 20:494-495. [Pub Med]

30. Maggio M, Cattabiani C, Lauretani F, Ferrucci L, Luci M, Valenti G, Ceda G. The concept of multiple hormonal dysregulation. Acta Biomed. 2010;81 Suppl 1:19-29. [Pub Med]

31. Meng H, Wamsley B, Liebel D, Dixon D, Eggert G, Van Nostrand J. Urban-rural differences in the effect of a Medicare health promotion and disease selfmanagement program on physical function and health care expenditures. Gerontologist. 2009;49:407-417. [Pub Med]

32. Morris JN, Fries BE, Mehr DR, Hawes C, Phillips C, Mor V, Lipsitz LA. MDS Cognitive Performance Scale. J Gerontol. 1994;49:M174-82. [Pub Med]

33. Ogihara $T$, Kikuchi K, Matsuoka $H$, Fujita T, Higaki J, Horiuchi M, Imai $Y$, Imaizumi T, Ito S, Iwao H, Kario K, Kawano Y, Kim-Mitsuyama S, Kimura G, Matsubara H, Matsuura H, Naruse M, Saito I, Shimada K, Shimamoto K, Suzuki H, Takishita S, Tanahashi N, Tsuchihashi T, Uchiyama M, Ueda S, Ueshima H, Umemura S, Ishimitsu T, Rakugi H; Japanese Society of Hypertension Committee. The Japanese Society of Hypertension Guidelines for the Management of Hypertension (JSH 2009). Hypertens Res. 2009 Jan; 32(1):3-107. [Pub Med]

34. O'Rourk MF, Namasivayam M, Adji A. Treatment of hypertension in patients 80 years of age or older. Minerva Med. 2009;100:25-38. [Pub Med]

35. Rockwood K, Song X, MacKnight C, Bergman H, Hogan DB, McDowell I, Mitnitski A. A global clinical measure of fitness and frailty in elderly people. CMAJ. 2005;30: 489-495. [Pub Med]

36. Rowe WJ, Kahn LR, Successful aging. Gerontologist 1997; 37:143-149. [Pub Med]

37. Searle SD, Mitnitski A, Gahbauer EA, Gill TM, Rockwood K. A standard procedure for creating a frailty index. BMC Geriatr. 2008;8:24. [Pub Med] 
38. Sharifi N, Gulley JL, Dahut WL. Androgen deprivation therapy for prostate cancer. JAMA. 2005; 294:238-244. [Pub Med]

39. Theou O, Jones GR, Overend TJ, Kloseck M, Vandervoort AA. An exploration of the association between frailty and muscle fatigue. Appl Physiol Nutr Metab. 2008;33:651-665.

40. Walston J, Fried LP. Frailty and the older man. Med Clin North Am. 1999;83: 1173-1194. [Pub Med]

41. Wieland D. The effectiveness and cost of comprehensive geriatric evaluation and management. Crit Rev Oncology/Mematology. 2003;48:227-237. [Pub Med]

42. Working Group on Functional Outcome Measure for Clinical Trials. Functional outcomes for clinical trials in frail older persons: time to be moving. J Gerontol A Biol Sci Med Sci. 2008;63:160-164. [Pub Med]

43. Yano Y, Inokuchi T, Hoshide S, Kanemaru Y, Shimada K, Kario K. Association of poor physical function and cognitive dysfunction with high nocturnal blood pressure level in treated elderly hypertensive patients. Am J Hypertens. 2011;24:285-91. [Pub Med] 


\section{CAPTIONS FOR TABLES}

Table 1: Final disposition of study subjects

Table 2: Baseline characteristics of frail versus non-frail participants (parametric variables)

Table 3: Baseline characteristics of frail versus non-frail participants (non-parametric variables, determined using the Fisher exact test).

Table 4: Variables near or reaching statistical significance according to multivariate logistic regression analysis

Table 5: Predictive scoring model for frailty 
Table 1. Final disposition of study subjects

\begin{tabular}{|c|c|c|c|c|}
\hline & Male & Female & Total & $\%$ \\
\hline Dropout & 13 & 21 & 34 & 8.4 \\
\hline Death & 14 & 8 & 22 & 5. 4 \\
\hline Frail/phone or mail & 11 & 34 & 45 & $\left(\begin{array}{lll}1 & 1 . & 0\end{array}\right)$ \\
\hline Frail/CGA & 8 & 12 & 20 & $(4.9)$ \\
\hline Frailty total & 19 & 46 & 65 & 16.0 \\
\hline Non-frail/phone or mail & 11 & 1 & 12 & $(2.9)$ \\
\hline Non-frailty/CGA & 127 & 147 & 274 & $\left(\begin{array}{l}67.3) \\
\text { ( } 3)\end{array}\right.$ \\
\hline Non-frailty/total & 138 & 148 & 286 & 70.2 \\
\hline Total & 184 & 223 & 407 & $\begin{array}{llll}1 & 0 & 0 & 0\end{array}$ \\
\hline
\end{tabular}


Table 2. Baseline Characteristics of frail versus non-frail participants (parametric variables)

\begin{tabular}{|c|c|c|c|}
\hline Parametric variables & Non-frail $(n=286)$ & Frail $(n=65)$ & $\mathrm{p}$ value \\
\hline Age (years) & $77 \pm 4$ & $78 \pm 4$ & 0.049 \\
\hline Height $(\mathrm{cm})$ & $156 \pm 8$ & $153 \pm 8$ & 0.032 \\
\hline Weight (kg) & $55 \pm 9$ & $52 \pm 9$ & 0.017 \\
\hline Body Mass Index & $23 \pm 3$ & $22 \pm 3$ & 0.256 \\
\hline Upper Arm Skin Fold (mm) & $15 \pm 7$ & $16 \pm 3$ & 0.617 \\
\hline Upper Arm Muscle Area $\left(\mathrm{cm}^{2}\right)$ & $38 \pm 9$ & $35 \pm 7$ & 0.015 \\
\hline Upper Arm Circumference $(\mathrm{cm})$ & $26 \pm 3$ & $26 \pm 3$ & 0.098 \\
\hline Calf Circumference $(\mathrm{cm})$ & $35 \pm 3$ & $34 \pm 3$ & 0.007 \\
\hline Bone Mineral Density $\left(\mathrm{g} / \mathrm{cm}^{2}\right)$ & $0.90 \pm 0.21$ & $0.82 \pm 0.20$ & 0.002 \\
\hline Hand Grip dominant side(kg) & $26 \pm 7$ & $22 \pm 7$ & $0.001^{*}$ \\
\hline Timed walk(sec/5 meters) & $2.7 \pm 0.5$ & $3.1 \pm 0.8$ & $0.000^{*}$ \\
\hline Resting Metabolic Rate (kcal/min) & $1.058 \pm 0.294$ & $0.987 \pm 0.225$ & 0.072 \\
\hline Audiometry right $2,000 \mathrm{~Hz}(\mathrm{~dB})$ & $29 \pm 18$ & $25 \pm 18$ & 0.169 \\
\hline Audiometry right $4,000 \mathrm{~Hz}(\mathrm{~dB})$ & $43 \pm 21$ & $41 \pm 20$ & 0.580 \\
\hline Audiometry left $2,000 \mathrm{~Hz}(\mathrm{~dB})$ & $29 \pm 18$ & $28 \pm 18$ & 0.727 \\
\hline Audiometry left $4,000 \mathrm{~Hz}(\mathrm{~dB})$ & $42 \pm 21$ & $42 \pm 21$ & 0.976 \\
\hline Systolic Pressure $(\mathrm{mmHg})$ & $135 \pm 17$ & $140 \pm 21$ & 0.046 \\
\hline Diastolic Pressure $(\mathrm{mmHg})$ & $78 \pm 10$ & $77 \pm 11$ & 0.796 \\
\hline Pulse Pressure $(\mathrm{mmHg})$ & $57 \pm 12$ & $64 \pm 18$ & $0.000^{*}$ \\
\hline Ankle Brachial Index & $1.15 \pm 0.09$ & $1.13 \pm 0.10$ & 0.128 \\
\hline Pulse Wave Velocity $(\mathrm{cm} / \mathrm{sec})$ & $1845 \pm 353$ & $1933 \pm 414$ & 0.080 \\
\hline Heart Rate (bpm) & $69 \pm 11$ & $70 \pm 12$ & 0.680 \\
\hline Hemoglobin $(\mathrm{g} / \mathrm{ml})$ & $13.6 \pm 1.3$ & $13.1 \pm 1.2$ & 0.002 \\
\hline Total Cholesterol $(\mathrm{mg} / \mathrm{dl})$ & $217 \pm 32$ & $214 \pm 34$ & 0.485 \\
\hline Serum Creatinine $(\mathrm{mg} / \mathrm{dl})$ & $0.81 \pm 0.22$ & $0.76 \pm 0.21$ & 0.099 \\
\hline Serum Total Protein $(\mathrm{g} / \mathrm{dl})$ & $7.2 \pm 0.4$ & $7.2 \pm 0.4$ & 0.576 \\
\hline Serum Albumin $(\mathrm{g} / \mathrm{dl})$ & $4.2 \pm 0.2$ & $4.2 \pm 0.2$ & 0.498 \\
\hline Serum Cortisol (micg/dl) & $10.9 \pm 9.5$ & $11.6 \pm 3.8$ & 0.188 \\
\hline Luteinizing Hormone $(\mathrm{ng} / \mathrm{ml})$ & $14 \pm 9$ & $19 \pm 11$ & 0.002 \\
\hline Dehydroepiandrosterone $(\mathrm{ng} / \mathrm{ml})$ & $756 \pm 435$ & $587 \pm 316$ & 0.003 \\
\hline C-Reactive Protein (mg/dl) & $1.11 \pm 0.43$ & $0.09 \pm 0.10$ & 0.450 \\
\hline Interleukin-6(pg/ml) & $2.01 \pm 2.95$ & $2.33 \pm 1.98$ & 0.410 \\
\hline Lymphocyte count $(n / \mu \mid)$ & $1179 \pm 544$ & $1711 \pm 554$ & 0.363 \\
\hline
\end{tabular}

*Significant by Bonferroni's correction for type I error $(p<0.05 / 33=0.0015$ 
Table 3. Baseline characteristics of frail versus non-frail participants (non-parametric variables, determined using the Fisher exact test)

\begin{tabular}{lccc} 
Nonparametric variables & Non-frail $(\mathrm{N}=286)$ & Frail $(\mathrm{n}=65)$ & Two-tailed $\mathrm{P}$ value \\
\hline Sex $(\mathrm{female} / \mathrm{male})$ & $148 / 138$ & $46 / 19$ & 0.006 \\
Hypertension $(\mathrm{a} / \mathrm{p})$ & $207 / 79$ & $46 / 19$ & 0.878 \\
Hypercholesterolemia $(\mathrm{a} / \mathrm{p})$ & $246 / 39$ & $54 / 10$ & 0.692 \\
Diabetes mellitus $(\mathrm{a} / \mathrm{p})$ & $258 / 27$ & $57 / 7$ & 0.649 \\
Smoking $(\mathrm{a} / \mathrm{p})$ & $263 / 23$ & $61 / 4$ & 0.798 \\
Living with spouse $(\mathrm{y} / \mathrm{n})$ & $130 / 156$ & $19 / 46$ & 0.018 \\
Living with others $(\mathrm{y} / \mathrm{n})$ & $103 / 183$ & $27 / 38$ & 0.477 \\
Frequent going out $(\mathrm{f} / \mathrm{r})$ & $145 / 118$ & $27 / 32$ & 0.198 \\
Appetite loss $(\mathrm{a} / \mathrm{p})$ & $276 / 10$ & $65 / 0$ & 0.218 \\
Cognitive change $(\mathrm{a} / \mathrm{p})$ & $159 / 127$ & $22 / 43$ & $0.002^{*}$ \\
Fall $(\mathrm{a} / \mathrm{p})$ & $233 / 53$ & $44 / 21$ & 0.018 \\
Fracture $(\mathrm{a} / \mathrm{p})$ & $256 / 30$ & $52 / 13$ & 0.056 \\
Hearing deficit $(\mathrm{a} / \mathrm{p})$ & $212 / 74$ & $34 / 31$ & $0.001^{*}$ \\
Pain $(\mathrm{a} / \mathrm{p})$ & $235 / 51$ & $46 / 19$ & 0.057 \\
Insomnia $(\mathrm{a} / \mathrm{p})$ & $216 / 70$ & $51 / 14$ & 0.748 \\
Urinary incontinence $(\mathrm{a} / \mathrm{p})$ & $256 / 31$ & $51 / 14$ & 0.037 \\
\hline
\end{tabular}

* Significant by Bonferroni's correction for type I error $(p<0.05 / 15=0.0033)$ Abbreviations: a(absent), $p$ (present), $y($ yes), $n($ no), f(frequent), $r($ rare). 
Table 4. List of parameters near or reaching significance according to multivariate logistic regression analysis

\begin{tabular}{lrccc} 
Variables & Walt value & Two-tail P value & Odds ratio & $\begin{array}{l}95 \% \text { confidence interval } \\
\text { of odds ratio }\end{array}$ \\
\hline Calf circumference & 3.374 & 0.066 & 1.794 & $0.962 \sim 3.347$ \\
Timed walk & 14.665 & 0.000 & 3.282 & $1.786 \sim 6.030$ \\
Pulse pressure & 5.767 & 0.016 & 2.074 & $1.144 \sim 3.761$ \\
Cognitive change & 9.389 & 0.002 & 2.641 & $1.419 \sim 4.915$ \\
Hearing deficit & 6.471 & 0.011 & 2.186 & $1.197 \sim 3.995$ \\
\hline
\end{tabular}


Table 5. Prediction scoring model for frailty

\begin{tabular}{lc} 
Variables & Score \\
\hline Timed walk $>=3$ secconds $/ 5$ meters & 1 \\
Pulse pressure $>=60 \mathrm{mmHg}$ & 1 \\
Cognitive change (yes) & 1 \\
Hearing deficit(yes) & 1 \\
\hline
\end{tabular}




\section{Highlights}

- Taking more than 3 seconds to walk 5 meters was a significant predictor of frailty.

- Others predictors were a wide pulse pressure, cognition and hearing deficits.

- We constructed a simple additive score for predicting frailty.

- A score of 0 had a 93\% negative predictive values for frailty.

- A score of 4 had a $70 \%$ positive predictive value for frailty. 